\title{
PLEKHS1: A new molecular marker predicting risk of progression of non-muscle-invasive bladder cancer
}

\author{
GÉRALDINE PIGNOT ${ }^{1}$, CONSTANCE LE GOUX $^{2}$, SOPHIE VACHER ${ }^{2}$, \\ ANNE SCHNITZLER $^{2}$, FRANÇOIS RADVANYI ${ }^{3}$, YVES ALLORY ${ }^{4}$, \\ FRANÇOIS LALLEMAND ${ }^{2}$, NICOLAS BARRY DELONGCHAMPS ${ }^{5}$, MARC ZERBIB ${ }^{5}$,

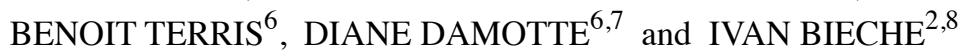 \\ ${ }^{1}$ Unit of Oncological Surgery 2, Paoli-Calmettes Institute, Marseille F-13009; ${ }^{2}$ Pharmacogenomics Unit, \\ Genetics Department, Institut Curie; ${ }^{3}$ Molecular Oncology Team, Institut Curie, UMR 144-CNRS; \\ ${ }^{4}$ Pathology Department, Institut Curie, Paris F-75005; ${ }^{5}$ Urology Department, Cochin Hospital, \\ Paris Descartes University, ${ }^{6}$ Pathology Department, Cochin Hospital, Paris Descartes University, \\ Paris F-75014; ${ }^{7}$ Cancer and Anti-tumor Immunity, INSERM U1138, Cordeliers Research Center; \\ ${ }^{8}$ Inserm U1016, Cochin Institute, Paris Descartes University, Paris F-75006, France
}

Received February 28, 2019; Accepted June 3, 2019

DOI: $10.3892 / 01.2019 .10706$

\begin{abstract}
Promoter mutations of pleckstrin homology domain-containing S1 (PLEKHS1) are frequent in several cancer types. To evaluate the DNA mutations, the mRNA expression and prognostic value of PLEKHSI was evaluated in bladder cancer. We investigated DNA mutations and mRNA expression of PLEKHS1 in a first series of 154 bladder tumors [71 non-muscle-invasive bladder cancer (NMIBC) and 83 muscle-invasive bladder cancers (MIBC)] from patients who underwent transurethral bladder resection or radical cystectomy between 2001 and 2006, and 20 normal bladder samples. Results were then validated in a second series of 181 bladder tumors (91 NMIBC and 90 MIBC). All patients have signed an informed consent form. DNA mutations were analysed by high-resolution melt analysis and sanger sequencing. The mRNA expression was measured by real-time reverse-transcriptase quantitative PCR. The results of the molecular analysis were compared with survival data. PLEKHS1 mutations occurred in 25.0 and $32.2 \%$ of NMIBC and MIBC, respectively in the first series. These results were confirmed in the second series (33.0 and 37.8\% of NMIBC and MIBC, respectively). In MIBC, DNA mutations were significantly more frequent with the basal than non-basal phenotype (61.5 vs. 27.1\%; $\mathrm{P}=0.0025$ ). The PLEKHSI mRNA level was increased in 22.5 and $27.7 \%$ of NMIBC and MIBC tumors
\end{abstract}

Correspondence to: Dr Constance Le Goux, Pharmacogenomics Unit, Genetics Department, Institut Curie, 26 Rue d'Ulm, Paris F-75005, France

E-mail: constance.legoux@gmail.com

Key words: bladder cancer, DNA mutations, molecular marker, prognosis, reverse transcription-PCR but was not associated with DNA mutations. In NMIBC, PLEKHSI mRNA overexpression was significantly associated with progression to muscle-invasive disease $(\mathrm{P}=0.0069)$ and remained an independent prognostic factor on multivariate analysis $(\mathrm{P}=0.034)$. DNA mutations of PLEKHSI occurred in one-third of bladder tumors and was frequent in the basal MIBC phenotype. PLEKHSI mRNA overexpression may be an independent prognostic factor of progression-free survival in NMIBC.

\section{Introduction}

Bladder cancer is the sixth most common cause of cancer mortality and its incidence has increased markedly in recent decades $(1,2)$ as well as an increasing prevalence of established risk factors such as smoking, overweight, physical inactivity, and changing reproductive patterns associated with urbanization and economic development. Based on GLOBOCAN estimates, about 14.1 million new cancer cases and 8.2 million deaths occurred in 2012 worldwide. Over the years, the burden has shifted to less developed countries, which currently account for about $57 \%$ of cases and $65 \%$ of cancer deaths worldwide. Lung cancer is the leading cause of cancer death among males in both more and less developed countries, and has surpassed breast cancer as the leading cause of cancer death among females in more developed countries; breast cancer remains the leading cause of cancer death among females in less developed countries. Other leading causes of cancer death in more developed countries include colorectal cancer among males and females and prostate cancer among males. In less developed countries, liver and stomach cancer among males and cervical cancer among females are also leading causes of cancer death. Although incidence rates for all cancers combined are nearly twice as high in more developed than in less developed countries in both males and females, mortality rates are only 8 to $15 \%$ higher in more 
developed countries. This disparity reflects regional differences in the mix of cancers, which is affected by risk factors and detection practices, and/or the availability of treatment. Risk factors associated with the leading causes of cancer death include tobacco use (lung, colorectal, stomach, and liver cancer. Current prognostic factors, namely TNM stage and pathological grade, insufficiently predict outcome at the individual level. The different outcome for patients with the same stage and grade calls for new prognostic molecular markers that may also serve as therapeutic targets.

Several high-throughput studies have focused on delineating genomic changes and gene expression in the various stages of bladder-cancer development and progression. Recent genomic analyses, part of The Cancer Genome Atlas, have identified several new target genes not previously described in bladder carcinogenesis (3-6).

Pleckstrin homology domain-containing S1 (PLEKHS1) is one of the most remarkable targets, because after telomerase reverse transcriptase (TERT), it is the second gene of the human genome showing frequent somatic non-coding mutations within its promoter (7). This gene, located on chromosome 10q25.3, encodes the PLEKHS1 protein with unknown function. These mutations are single-nucleotide substitutions in the PLEKHSI proximal promoter (in intron 1 with a non-coding exon 1 from NM_024889.4): substitutions that effect guanine at position Chr.10: 115511590 and cytosine at position Chr.10: 115511593 from the GRCh37 (hg19) genomic coordinate (or c.-20+70G and c.-20+73C from NM_024889.4). These mutations are close to the translation start site of the PLEKHSI gene $(-3,447$ and $-3,444$ bp upstream of the translation start site) and are flanked by stretches of $10 \mathrm{bp}$ on both sides that are palindromic to each other. The two PLEKHSI promoter mutations could be considered among the most common noncoding mutations in cancer. In bladder cancer, almost $40 \%$ of tumors could be affected by promoter mutations of this gene (8). However, data on messenger ribonucleic acid (mRNA) expression levels in bladder cancer are still lacking.

We analyzed the frequency of promoter mutations and mRNA expression of PLEKHS1 in two large series of 335 bladder tumors: 162 non-muscle-invasive bladder cancer (NMIBC) (71 and 91, respectively) and 173 muscle-invasive bladder cancers (MIBC) (83 and 90, respectively). A retrospective review of patient outcomes allowed for performing survival analyses to highlight the putative prognostic value of this gene.

\section{Patients and methods}

Patients and samples. We analyzed samples from two series of patients with urothelial carcinoma of the bladder. The first series consisted of 154 patients who had undergone transurethral bladder resection or a radical cystectomy in our hospital between 2002 and 2007. Immediately after surgery, tumor samples from each patient were frozen in liquid nitrogen and stored at $-80^{\circ} \mathrm{C}$ [for DNA (deoxyribonucleic acid) and RNA extraction] and fixed in formaldehyde. Specimens of normal bladder tissue from 20 patients undergoing surgery unrelated to bladder tumors (transurethral resection of the prostate, prostatic adenomectomy) were used as sources of normal bladder tissues.
Each tumor was reviewed by two pathologists (DD and MS) who were blinded to the clinical outcomes. Tumors were re-staged according to the 2009 TNM classification of bladder tumors (9) and were graded according to the WHO 2004 tumor-grading scheme (10). Standard follow-up visits followed current guidelines.

The second series was collected from 181 patients treated surgically between 1988 and 2006 at Henri Mondor Hospital, Institut Gustave Roussy (Villejuif, France) and Foch Hospital (Suresnes, France). Pure SCC and pure adenocarcinoma were excluded. Immediately after surgery, tumor samples from each patient were frozen in liquid nitrogen and stored at $-80^{\circ} \mathrm{C}$ (for DNA and RNA extraction) and fixed in formaldehyde. For non muscle invasive cases (stage Ta or T1), TURB material was used; for muscle invasive cases, TURB or cystectomy material was used, without prior neoadjuvant chemotherapy, as previously described in Rebouissou et al (11).

All patients provided written informed consent. These studies received approval from an institutional review board, Centre d'Éthique Clinique de l'Hôpital Cochin, and was conducted according to the principles outlined in the Declaration of Helsinki.

DNA mutation analysis. PLEKHSI has two mutational spots that are well described. The assessment was performed by a screening with high-resolution melt (HRM) analysis followed by Sanger sequencing of samples with a mutated profile on HRM to validate the HRM data and determine the nomenclature of mutations found. The nucleotide sequences for the primers were for PLEKHSI-U (5'-CTTCCAAGGCTGGGA TGATCTA-3') and PLEKHSI-L (5'-AAGAAAGTGCCC ATAACAGAAATACA-3') (polymerase chain reaction (PCR) product of $107 \mathrm{bp}$ ).

Real-time RT-qPCR. The theoretical basis, primers and PCR consumables, RNA extraction, complementary deoxyribonucleic acid (cDNA) synthesis, and PCR-reaction conditions were previously described in detail (12). One endogenous RNA control gene was chosen, namely $T B P$ (GenBank accession no. NM_003194), which encodes the TATA box-binding protein. Because PLEKHS1 was expressed in tumor samples but not normal bladder tissue, values were normalized so that a Ct value of 35 was set to 1 . Taking into account the optimal cut-off for PLEKHSI, mRNA values $\geq 100$ were considered overexpression.

Primers were chosen with the assistance of the Oligo 6.0 computer program (National Biosciences, Plymouth, MN). The nucleotide primer sequences were PLEKHSI-U (5'-AAGATG TTTAAATGCCACCCTGATG-3') and PLEKHS1-L (5'-CCA GTCTTTAATCTTCTCCCTGTCGT-3') (PCR product of $99 \mathrm{bp}$ ). Experiments were performed in duplicate for each data point.

Statistical analysis. The clinicopathologic features of NMIBC and MIBC were tested for their association with tumor recurrence and survival by Student's t-test for continuous variables or $\chi^{2}$ test for qualitative variables. The distribution of mRNA levels was described with medians (range). Relationships between clinical and histological variables and mRNA levels of PLEKHSI were tested by the non-parametric Mann-Whitney 
Table I. Clinical, pathological and survival characteristics of the 71 NMIBC of the first series.

\begin{tabular}{|c|c|c|c|c|c|c|}
\hline \multirow[b]{2}{*}{ Characteristic } & \multirow[b]{2}{*}{ Whole population, n (\%) } & \multirow[b]{2}{*}{ No recurrence, $\mathrm{n}(\%)$} & \multicolumn{2}{|c|}{ Recurrence } & \multicolumn{2}{|c|}{$\begin{array}{c}\text { Muscle-invasive } \\
\text { progression }\end{array}$} \\
\hline & & & $\mathrm{n}(\%)$ & $\mathrm{P}$-value ${ }^{\mathrm{a}}$ & $\mathrm{n}(\%)$ & P-value \\
\hline Total population & $71(100.0)$ & $25(35.2)$ & $36(50.7)$ & & $10(14.1)$ & \\
\hline Age (years) & & & & & & 0.08 \\
\hline$\geq 60$ & 56 (78.9) & $19(76.0)$ & $27(75.0)$ & 0.93 & $10(100.0)$ & \\
\hline$<60$ & $15(21.1)$ & $6(24.0)$ & $9(25.0)$ & & $0(0.0)$ & \\
\hline \multicolumn{7}{|l|}{ Sex } \\
\hline Male & 63 (88.7) & $22(88.0)$ & 32 (88.9) & 0.91 & $9(90.0)$ & 0.89 \\
\hline Female & $8(11.3)$ & $3(12.0)$ & $4(11.1)$ & & $1(10.0)$ & \\
\hline \multicolumn{7}{|l|}{ Smoking status } \\
\hline Non-smoker & 33 (46.5) & $13(52.0)$ & $15(41.7)$ & 0.43 & $5(50.0)$ & 0.81 \\
\hline Smoker & $38(53.5)$ & $12(48.0)$ & $21(58.3)$ & & $5(50.0)$ & \\
\hline \multicolumn{7}{|c|}{ History of NMIBC } \\
\hline No & $39(54.9)$ & $22(88.0)$ & $13(36.1)$ & $<0.0001$ & $4(40.0)$ & 0.31 \\
\hline Yes & $32(45.1)$ & $3(12.0)$ & $23(63.9)$ & & $6(60.0)$ & \\
\hline \multicolumn{7}{|l|}{ Associated pTis } \\
\hline No & $69(97.2)$ & $25(100.0)$ & $36(100.0)$ & 0.99 & $8(80.0)$ & 0.0004 \\
\hline Yes & $2(2.8)$ & $0(0.0)$ & $0(0.0)$ & & $2(20.0)$ & \\
\hline \multicolumn{7}{|l|}{ Grade } \\
\hline Low & $25(35.2)$ & $10(40.0)$ & $14(38.9)$ & 0.93 & $1(10.0)$ & 0.07 \\
\hline High & $46(64.8)$ & $15(60.0)$ & $22(61.1)$ & & $9(90.0)$ & \\
\hline \multicolumn{7}{|l|}{ Tumor stage } \\
\hline $\mathrm{Ta}$ & $42(59.2)$ & $15(60.0)$ & $24(66.7)$ & 0.59 & $3(30.0)$ & 0.043 \\
\hline T1 & $29(40.8)$ & $10(40.0)$ & $12(33.3)$ & & $7(70.0)$ & \\
\hline
\end{tabular}

${ }^{\mathrm{a}} \chi^{2}$ test (recurrence vs no recurrence); ${ }^{\mathrm{b}} \chi^{2}$ test (muscle-invasive progression vs. others). NMIBC, non-muscle-invasive bladder cancer.

U test and Kruskal-Wallis H-test. Overall survival (OS) was calculated from the date of surgery until death or the last follow-up. Recurrence-free survival (RFS) was defined as the time from the date of surgery to the first local relapse or first metastasis. For NMIBC, progression-free survival (PFS) was defined as the time from the date of surgery to progression to muscle-invasive disease. Survival curves were derived from Kaplan-Meier estimates. The log-rank test was used to compare survival between subgroups. The prognostic impact of mRNA levels, adjusted for the other prognostic factors, was assessed by Cox proportional-hazards regression analysis, estimating hazard ratios and $95 \%$ confidence intervals. The variables significant in univariate analysis $(\mathrm{P}<0.10)$ were included in multivariate analysis. Differences were considered significant at $\mathrm{P}<0.05$.

\section{Results}

Clinicopathologic characteristics of the cohorts. Complete clinical, histological and survival data were obtained from medical records for these 154 patients [129 men and 25 women; median age 70 years (range, 31-91)]. Pathological staging showed NMIBC in 71 patients (25 low-grade pTa,
17 high-grade pTa, 29 high-grade pT1) and high-grade MIBC in 83 patients. For NMIBC, the median follow-up was 57.4 months (range, 1-158 months; mean follow-up, 61 months). For MIBC, the median follow-up was 12.5 months (range, 1-152 months; mean follow-up, 29 months). In the MIBC cohort, 12 patients $(14.5 \%)$ received neoadjuvant chemotherapy before cystectomy and 25 (30.1\%) received adjuvant chemotherapy taking into account pathological characteristics of the tumor and renal function. Clinical, histological and survival characteristics for the first series are presented in Tables I and II.

The second series consisted of an independent cohort of 181 patients with bladder cancer [150 men and 31 women; median age 67 years (range, 30-95)]. Pathological staging showed NMIBC in 91 patients (33 low-grade pTa, 17 high-grade pTa, 41 high-grade pT1) and high-grade MIBC in 90 patients. In this second cohort, molecular subgroups (basal phenotype, called MC7, vs non-basal phenotype) were previously determined by using the CIT (Carte d'Identité des Tumeurs) classification (11) we identified an MIBC subgroup accounting for $23.5 \%$ of MIBC, associated with shorter survival and displaying a basal-like phenotype, as shown by the expression of epithelial basal cell 
Table II. Clinical, pathological and survival characteristics of the 83 muscle-invasive bladder cancer of the first series.

\begin{tabular}{|c|c|c|c|c|c|}
\hline \multirow[b]{2}{*}{ Characteristic } & \multirow[b]{2}{*}{ Whole population, n (\%) } & \multicolumn{2}{|c|}{ Disease-free survival } & \multicolumn{2}{|c|}{ Overall survival } \\
\hline & & Number of events $(\%)^{\mathrm{a}}$ & P-value ${ }^{c}$ & Number of events $(\%)^{b}$ & P-value \\
\hline Total population & $83(100.0)$ & $48(57.8)$ & & $46(55.4)$ & \\
\hline \multicolumn{6}{|l|}{ Age (years) } \\
\hline$\geq 60$ & $61(73.5)$ & $40(65.5)$ & 0.017 & 39 (63.9) & 0.009 \\
\hline$<60$ & $22(26.5)$ & $8(36.4)$ & & $7(31.8)$ & \\
\hline \multicolumn{6}{|l|}{ Sex } \\
\hline Male & 66 (79.5) & $36(54.5)$ & 0.23 & 38 (57.6) & 0.44 \\
\hline Female & $17(20.5)$ & $12(70.6)$ & & $8(47.1)$ & \\
\hline \multicolumn{6}{|l|}{ Smoking status } \\
\hline Non-smoker & $34(41.0)$ & $18(52.9)$ & 0.45 & $12(35.3)$ & 0.002 \\
\hline Smoker & $49(59.0)$ & $30(61.2)$ & & $34(69.4)$ & \\
\hline \multicolumn{6}{|l|}{ History of NMIBC } \\
\hline No & $59(71.1)$ & $30(50.8)$ & 0.043 & $31(52.5)$ & 0.41 \\
\hline Yes & $24(28.9)$ & $18(75.0)$ & & $15(62.5)$ & \\
\hline \multicolumn{6}{|l|}{ Associated pTis } \\
\hline No & $73(88.0)$ & $43(58.9)$ & 0.59 & $40(54.8)$ & 0.76 \\
\hline Yes & $10(12.0)$ & $5(50.0)$ & & $6(60.0)$ & \\
\hline \multicolumn{6}{|l|}{ Tumor stage } \\
\hline $\mathrm{T} 2$ & $34(41.0)$ & $17(50.0)$ & 0.10 & $13(38.2)$ & 0.009 \\
\hline$\geq \mathrm{T} 3$ & $49(59.0)$ & $31(63.3)$ & & $33(67.3)$ & \\
\hline \multicolumn{6}{|l|}{ Lymph node status } \\
\hline $\mathrm{N}-$ & $58(69.9)$ & $27(46.6)$ & 0.002 & $25(43.1)$ & 0.0006 \\
\hline $\mathrm{N}+$ & $25(30.1)$ & $21(84.0)$ & & $21(84.0)$ & \\
\hline
\end{tabular}

${ }^{\mathrm{a}}$ First recurrence (local or metastatic); ${ }^{\mathrm{b}}$ Death; ${ }^{\mathrm{c}} \chi^{2}$ test. NMIBC, non-muscle-invasive bladder cancer.

markers. Basal-like tumors presented an activation of the epidermal growth factor receptor (EGFR). None patient of the second cohort received neoadjuvant chemotherapy. As in the first cohort, patients received adjuvant chemotherapy taking into account pathological characteristics of the tumor if they were eligible. Clinical and histological variables did not differ between the two series, except for history of NMIBC (Table III).

DNA mutations of PLEKHS1. DNA mutation analysis involved 103 available tumor DNA samples (44 NMIBC and 59 MIBC) from the first series and 18 normal bladder samples, then the 181 tumor samples (91 NMIBC and 90 MIBC) from the second series.

In the first series, 11/44 NMIBC (25.0\%) and 19/59 MIBC (32.2\%) samples had a promoter-mutated profile (Table IV). The PLEKHS1 promoter exhibited recurrent mutations at two genomic positions: c. $-20+70(\mathrm{G}>\mathrm{A}$ and $\mathrm{G}>\mathrm{C})$ and c. $-20+73$ $(\mathrm{C}>\mathrm{A}, \mathrm{C}>\mathrm{T}$ and $\mathrm{C}>\mathrm{G})$. NMIBC and MIBC samples did not differ by type of mutation $(\mathrm{P}=0.43)$.

In the second series, 30/91 NMIBC (33.0\%) and $34 / 90$ MIBC $(37.8 \%)$ samples had a promoter-mutated profile (Table IV). The DNA-mutated profile was not significantly associated with clinical parameters for patients with NMIBC
(Table V) or MIBC (Table VI). Regarding molecular subgroups in MIBC, a DNA-mutated profile was significantly more frequent with the basal phenotype (MC7) than the non-basal phenotype (61.5 vs. $27.1 \%, \mathrm{P}=0.0025)$. PLEKHS1 DNA mutation was not associated with prognosis, in terms of recurrence or progression with NMIBC and in terms of RFS or OS with MIBC (data not shown).

mRNA expression of PLEKHS1. The mRNA expression of PLEKHS1 was assessed in the first series $(\mathrm{n}=154)$. The median mRNA PLEKHS1 level was 19.7 [range, 0.0-972.6] with NMIBC and 25.7 [0.0-2288.1] with MIBC, vs. 0.0 [0.0-21.4] in normal bladder samples. PLEKHS1 was overexpressed in NMIBC and MIBC versus normal bladder tissue $(\mathrm{P}=0.00031$ and $\mathrm{P}=0.000025)$, with no difference in level between NMIBC and MIBC $(\mathrm{P}=0.51)$. Overall, 22.5 and $27.7 \%$ of NMIBC and MIBC tumors showed PLEKHS1 overexpression (vs. $0 \%$ in normal bladder samples, $\mathrm{P}<0.01)$. PLEKHS1 mRNA level was not associated with DNA mutations in NMIBC $(\mathrm{P}=0.39)$ or $\operatorname{MIBC}(\mathrm{P}=0.84)$.

Prognostic value of PLEKHS1 mRNA overexpression. PLEKHS1 mRNA overexpression was not significantly associated with clinical variables in NMIBC (Table VII) or MIBC 
Table III. Clinical and pathological characteristics of NMIBC and MIBC the two series.

\begin{tabular}{|c|c|c|c|c|}
\hline \multicolumn{5}{|l|}{ A, NMIBC } \\
\hline Characteristic & Whole population, $\mathrm{n}(\%)$ & First series, n (\%) & Second series, n (\%) & $\mathrm{P}$-value ${ }^{\mathrm{h}}$ \\
\hline Total population & $162(100.0)$ & $71(100.0)$ & $91(100.0)$ & \\
\hline \multicolumn{5}{|l|}{ Age (years) $)^{\mathrm{a}}$} \\
\hline$\geq 60$ & $108(72.0)$ & $56(78.9)$ & $52(65.8)$ & \multirow[t]{2}{*}{0.08} \\
\hline$<60$ & $42(28.0)$ & $15(21.1)$ & $27(34.2)$ & \\
\hline \multicolumn{5}{|l|}{ Sex } \\
\hline Male & $138(85.2)$ & $63(88.7)$ & $75(82.4)$ & \multirow[t]{2}{*}{0.26} \\
\hline Female & $24(14.8)$ & $8(11.3)$ & $16(17.6)$ & \\
\hline \multicolumn{5}{|c|}{ History of NMIBC ${ }^{b}$} \\
\hline No & $108(71.5)$ & $39(54.9)$ & $69(86.3)$ & \multirow[t]{2}{*}{$<0.0001$} \\
\hline Yes & $43(28.5)$ & $32(45.1)$ & $11(13.7)$ & \\
\hline \multicolumn{5}{|l|}{ Associated $\mathrm{pTis}^{\mathrm{c}}$} \\
\hline No & $134(93.7)$ & $69(97.2)$ & $65(90.3)$ & \multirow[t]{2}{*}{0.09} \\
\hline Yes & $9(6.3)$ & $2(2.8)$ & $7(9.7)$ & \\
\hline \multicolumn{5}{|l|}{ Grade } \\
\hline Low & $58(35.8)$ & $25(35.2)$ & $33(36.3)$ & \multirow[t]{2}{*}{0.89} \\
\hline High & $104(64.2)$ & $46(64.8)$ & $58(63.7)$ & \\
\hline \multicolumn{5}{|l|}{ Tumor stage } \\
\hline $\mathrm{Ta}$ & $92(56.8)$ & $42(59.2)$ & $50(54.9)$ & \multirow[t]{2}{*}{0.59} \\
\hline $\mathrm{T} 1$ & $70(43.2)$ & $29(40.8)$ & $41(45.1)$ & \\
\hline
\end{tabular}

$\mathrm{B}, \mathrm{MIBC}$

\begin{tabular}{|c|c|c|c|c|}
\hline Characteristic & Whole population, $\mathrm{n}(\%)$ & First series, n (\%) & Second series, n (\%) & $\mathrm{P}$-value ${ }^{\mathrm{h}}$ \\
\hline Total population & $173(100.0)$ & $83(100.0)$ & $90(100.0)$ & \\
\hline \multicolumn{5}{|l|}{ Age $(\text { years })^{d}$} \\
\hline$\geq 60$ & $124(73.8)$ & $61(73.5)$ & $63(74.1)$ & \multirow[t]{2}{*}{0.93} \\
\hline$<60$ & $44(26.6)$ & $22(26.5)$ & $22(25.9)$ & \\
\hline \multicolumn{5}{|l|}{ Sex } \\
\hline Male & $141(81.5)$ & $66(79.5)$ & $75(83.3)$ & \multirow[t]{2}{*}{0.52} \\
\hline Female & $32(18.5)$ & $17(20.5)$ & $15(16.7)$ & \\
\hline \multicolumn{5}{|c|}{ History of NMIBC ${ }^{e}$} \\
\hline No & $135(84.4)$ & $73(88.0)$ & $62(80.5)$ & \multirow[t]{2}{*}{0.20} \\
\hline Yes & $25(15.6)$ & $10(12.0)$ & $15(19.5)$ & \\
\hline \multicolumn{5}{|l|}{ Associated pTis ${ }^{\mathrm{f}}$} \\
\hline No & $135(84.4)$ & $73(88.0)$ & $62(80.5)$ & \multirow[t]{2}{*}{0.20} \\
\hline Yes & $25(15.6)$ & $10(12.0)$ & $15(19.5)$ & \\
\hline \multicolumn{5}{|l|}{ Tumor stage } \\
\hline $\mathrm{T} 2$ & $66(38.2)$ & $34(41.0)$ & $32(35.6)$ & \multirow[t]{2}{*}{0.46} \\
\hline$\geq \mathrm{T} 3$ & $107(61.8)$ & $49(59.0)$ & $58(64.4)$ & \\
\hline \multicolumn{5}{|c|}{ Lymph node status ${ }^{\mathrm{g}}$} \\
\hline $\mathrm{N}^{-}$ & $93(63.7)$ & $58(69.9)$ & $35(55.6)$ & \multirow[t]{2}{*}{0.07} \\
\hline $\mathrm{N}^{+}$ & $53(36.3)$ & $25(30.1)$ & $28(44.4)$ & \\
\hline
\end{tabular}

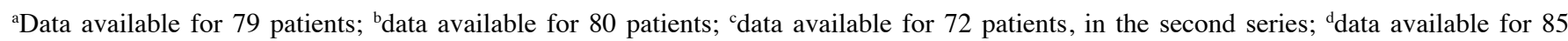
patients; ${ }^{\mathrm{e}}$ data available for 83 patients; ${ }^{\mathrm{f}}$ data available for 77 patients; ${ }^{\mathrm{g}}$ data available for 63 patients, in the second series. ${ }^{\mathrm{h}} \chi^{2}$ test. NMIBC, non-muscle-invasive bladder cancer; MIBC, muscle-invasive bladder cancer.

(Table VIII). With NMIBC, PLEKHS1 overexpression was associated with worse PFS on univariate analysis $(\mathrm{P}=0.0069)$ (Fig. 1). Five- and 10-year PFS rates were 72.4 and $38.8 \%$ with PLEKHS1 overexpression versus 88.9 and $88.7 \%$ without PLEKHS1 overexpression. Other clinical variables affecting PFS on univariate analysis with $\mathrm{P}<0.10$ on log-rank test 
Table IV. Frequency of mutations in the PLEKHS1 promoter in the two series.

\begin{tabular}{|c|c|c|c|c|c|c|}
\hline \multirow[b]{2}{*}{ PLEKHS1 profile } & \multicolumn{3}{|c|}{ First series $(n=103)$} & \multicolumn{3}{|c|}{ Second series $(n=181)$} \\
\hline & Mutated n (\%) & Not mutated n $(\%)$ & P-value ${ }^{a}$ & Mutated n (\%) & Not mutated n $(\%)$ & P-value ${ }^{a}$ \\
\hline All tumors & $30(29.1)$ & 73 (70.9) & & $64(35.4)$ & $117(64.4)$ & \\
\hline NMIBC & $11(25.0)$ & $33(75.0)$ & 0.43 & $30(33.0)$ & $61(67.0)$ & 0.50 \\
\hline MIBC & $19(32.2)$ & $40(67.8)$ & & $34(37.8)$ & $56(62.2)$ & \\
\hline
\end{tabular}

${ }^{a} \chi^{2}$ test. PLEKHS1, pleckstrin homology domain-containing S1; NMIBC, non-muscle-invasive bladder cancer; MIBC, muscle-invasive bladder cancer.

Table V. Association of clinicopathological variables and PLEKHS1 DNA mutated profile with NMIBC from the second series.

\begin{tabular}{|c|c|c|c|c|}
\hline Characteristic & Total population, n (\%) & PLEKHS1 mutated, n (\%) & Not mutated, n (\%) & P-value ${ }^{a}$ \\
\hline Total & $91(100.0)$ & $30(33.0)$ & $61(67.0)$ & \\
\hline \multicolumn{5}{|l|}{ Age (years) $)^{b}$} \\
\hline$\geq 60$ & $52(65.8)$ & $17(32.7)$ & $35(67.3)$ & \multirow[t]{2}{*}{0.95} \\
\hline$<60$ & $27(34.2)$ & $9(33.3)$ & $18(66.7)$ & \\
\hline \multicolumn{5}{|l|}{ Sex } \\
\hline Male & $75(82.4)$ & $26(35.1)$ & $48(64.9)$ & \multirow[t]{2}{*}{0.74} \\
\hline Female & $16(17.6)$ & $4(26.7)$ & $11(73.3)$ & \\
\hline \multicolumn{5}{|c|}{ History of NMIBC ${ }^{\mathrm{c}}$} \\
\hline No & $69(86.3)$ & $26(37.7)$ & $43(62.3)$ & \multirow[t]{2}{*}{0.36} \\
\hline Yes & $11(13.7)$ & $2(18.2)$ & $9(81.8)$ & \\
\hline \multicolumn{5}{|c|}{ Associated pTis ${ }^{\mathrm{d}}$} \\
\hline No & $65(90.3)$ & $21(32.3)$ & $44(67.7)$ & \multirow[t]{2}{*}{0.37} \\
\hline Yes & $7(9.7)$ & $4(57.1)$ & $3(42.9)$ & \\
\hline \multicolumn{5}{|l|}{ Grade } \\
\hline Low & $33(36.3)$ & $7(21.2)$ & $26(78.8)$ & \multirow[t]{2}{*}{0.098} \\
\hline High & $58(63.7)$ & $21(38.2)$ & $34(61.8)$ & \\
\hline \multicolumn{5}{|l|}{ Tumor stage } \\
\hline $\mathrm{Ta}$ & $50(54.9)$ & $14(28.0)$ & $36(72.0)$ & \multirow[t]{2}{*}{0.27} \\
\hline $\mathrm{T} 1$ & $41(45.1)$ & $16(39.0)$ & $25(61.0)$ & \\
\hline \multicolumn{5}{|l|}{ Phenotype $^{\mathrm{e}}$} \\
\hline Basal & $1(1.3)$ & $0(0.0)$ & $1(100.0)$ & \multirow[t]{2}{*}{0.76} \\
\hline Non-basal & $78(98.7)$ & $26(33.3)$ & $52(66.7)$ & \\
\hline
\end{tabular}

${ }^{\mathrm{a}} \chi^{2}$ test. ${ }^{\mathrm{b}}$ Data available for 79 patients; ${ }^{\mathrm{c}}$ data available for 80 patients; ${ }^{\mathrm{d}}$ data available for 72 patients; ${ }^{\mathrm{e}}$ data available for 79 patients. PLEKHS1, pleckstrin homology domain-containing S1; NMIBC, non-muscle-invasive bladder cancer.

included $\mathrm{T}$ stage and grade and were retained for multivariate analysis. On multivariate analysis, PLEKHS1 overexpression remained an independent prognostic factor of PFS $(\mathrm{P}=0.034)$ (Table IX).

Overall, 21/28 patients (75\%) who received Bacillus Calmette-Guerin (BCG) therapy showed recurrent NMIBC or progression to an invasive tumor during follow-up, including $15(53.6 \%)$ within the first 2 years. The median PLEKHS1 mRNA level was higher but not significantly with BCG-refractory tumor or early recurrence ( $<24$ months) than for $\mathrm{BCG}$ responders (no recurrence or $>24$ months): 40.8 [range, $0.0-375.5]$ vs. 15.2 [0.6-381.6] $(\mathrm{P}=0.80)$.

With MIBC, PLEKHS1 overexpression was not associated with RFS or OS $(\mathrm{P}=0.33$ and $\mathrm{P}=0.057$, respectively).

\section{Discussion}

Mutations of PLEKHS1 are non-coding and are located in the gene promoter and therefore cannot be detected by whole-exome analyses. This is also the case for non-coding 
Table VI. Association of clinicopathological variables and PLEKHS1 DNA mutated profile with MIBC from the second series.

\begin{tabular}{|c|c|c|c|c|}
\hline Characteristic & Total population, n (\%) & PLEKHS1 mutated, n (\%) & Not mutated, n (\%) & P-value ${ }^{a}$ \\
\hline Total & $90(100)$ & $34(64.8)$ & $56(35.2)$ & \\
\hline \multicolumn{5}{|l|}{$\mathrm{Age}^{\mathrm{b}}$} \\
\hline$\geq 60$ & $63(74.1)$ & $26(41.3)$ & $37(58.7)$ & \multirow[t]{2}{*}{0.24} \\
\hline$>60$ & $22(25.9)$ & $6(27.3)$ & $16(72.7)$ & \\
\hline \multicolumn{5}{|l|}{ Sex } \\
\hline Male & $75(83.3)$ & $29(38.7)$ & $46(61.3)$ & \multirow[t]{2}{*}{0.70} \\
\hline Female & $15(16.7)$ & $5(33.3)$ & $10(66.7)$ & \\
\hline \multicolumn{5}{|c|}{ History of NMIBC ${ }^{\mathrm{c}}$} \\
\hline No & $71(85.5)$ & $26(36.6)$ & $45(63.4)$ & \multirow[t]{2}{*}{0.38} \\
\hline Yes & $12(14.5)$ & $6(50.0)$ & $6(50.0)$ & \\
\hline \multicolumn{5}{|c|}{ Associated pTis ${ }^{\mathrm{d}}$} \\
\hline No & $62(80.5)$ & $25(40.3)$ & $37(59.7)$ & \multirow[t]{2}{*}{0.62} \\
\hline Yes & $15(19.5)$ & $5(33.3)$ & $10(66.7)$ & \\
\hline \multicolumn{5}{|l|}{ Tumor stage } \\
\hline $\mathrm{T} 2$ & $32(35.6)$ & $16(50.0)$ & $16(50.0)$ & \multirow[t]{2}{*}{0.076} \\
\hline$\geq \mathrm{T} 3$ & $58(64.4)$ & $18(31.0)$ & $40(69.0)$ & \\
\hline \multicolumn{5}{|c|}{ Lymph node status ${ }^{\mathrm{e}}$} \\
\hline $\mathrm{N}-$ & $35(55.6)$ & $14(40.0)$ & $21(60.0)$ & \multirow[t]{2}{*}{0.52} \\
\hline $\mathrm{N}+$ & $28(44.4)$ & $9(32.1)$ & $19(67.9)$ & \\
\hline \multicolumn{5}{|l|}{ Phenotype $^{\mathrm{f}}$} \\
\hline Basal & $26(30.6)$ & $16(61.5)$ & $10(38.5)$ & \multirow[t]{2}{*}{0.0025} \\
\hline Non-basal & $59(69.4)$ & $16(27.1)$ & $43(72.9)$ & \\
\hline
\end{tabular}

${ }^{\mathrm{a}} \chi^{2}$ test. ${ }^{\mathrm{b}} \mathrm{Data}$ available for 85 patients; ${ }^{\mathrm{c}}$ data available for 83 patients; ${ }^{\mathrm{d}}$ data available for 77 patients; ${ }^{\mathrm{e}}$ data available for 63 patients; ${ }^{\mathrm{f}}$ data available for 85 patients. PLEKHS1, pleckstrin homology domain-containing S1; MIBC, muscle-invasive bladder cancer.

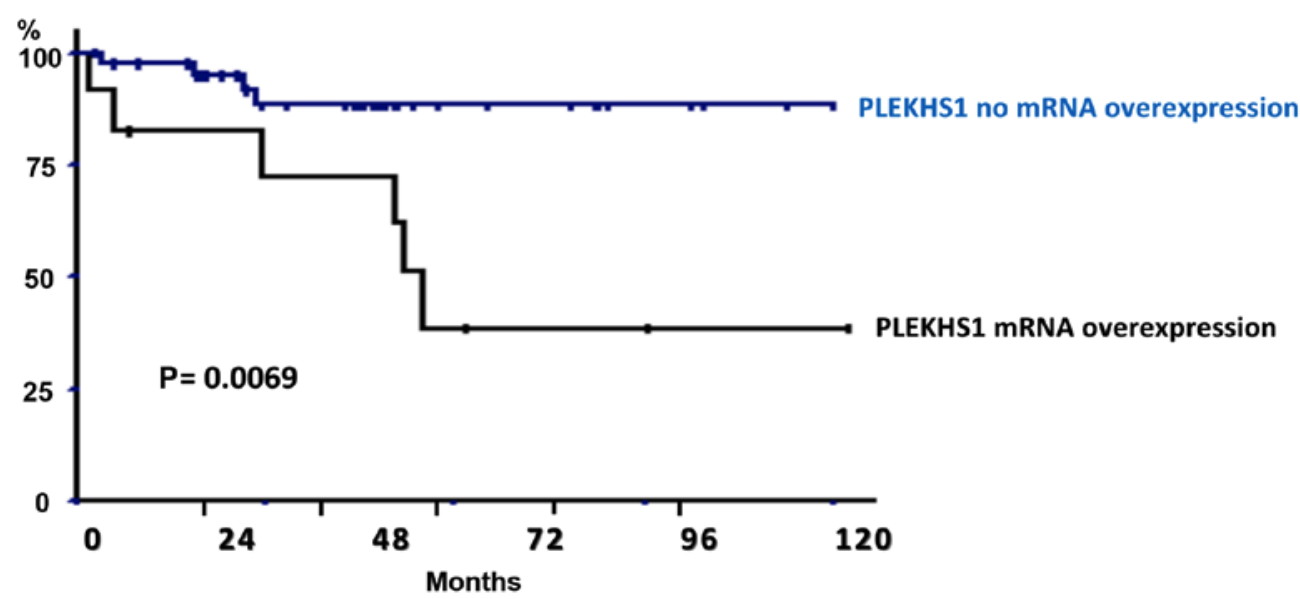

Figure 1. Progression-free survival with non-muscle-invasive bladder cancer by PLEKHS1 mRNA expression. PLEKHS1, pleckstrin homology domain-containing S1.

mutations located on the upstream regulatory sequences for genes such as TERT, WD repeat domain 74 (WDR74) and succinate dehydrogenase complex subunit D (SDHD) (8). Point mutations in the TERT promoter are the best known and occur in a subset of tumors with clinical interest. In bladder urothelial carcinomas, almost two thirds of tumors show somatic test mutations (13).
To our knowledge, this is the first study to assess PLEKHS1 DNA mutations and mRNA expression in bladder cancer. This assessment is of outmost importance because the association of gene expression and the prognostic impact of promoter mutations in the cancer remain unknown. Whole-genome sequencing of non-coding somatic mutations, rather than these exome studies, might provide answers to these deliberations. 
Table VII. Association of clincopathological variables and PLEKHS1 mRNA level with NMIBC from the first series.

\begin{tabular}{|c|c|c|c|c|}
\hline Characteristic & $\begin{array}{c}\text { Total } \\
\text { population, } \mathrm{n}(\%)\end{array}$ & $\begin{array}{c}\text { PLEKHS1 mRNA } \\
\text { no overexpression, } \mathrm{n}(\%)\end{array}$ & $\begin{array}{c}\text { PLEKHS1 mRNA } \\
\text { overexpression, } \mathrm{n}(\%)\end{array}$ & P-value ${ }^{a}$ \\
\hline Total & $71(100)$ & $55(77.5)$ & $16(22.5)$ & \\
\hline \multicolumn{5}{|l|}{ Age } \\
\hline$\geq 60$ & $56(78.9)$ & $43(76.8)$ & $13(23.2)$ & \multirow[t]{2}{*}{0.79} \\
\hline$<60$ & $15(21.1)$ & $12(80.0)$ & $3(20.0)$ & \\
\hline \multicolumn{5}{|l|}{ Sex } \\
\hline Male & $63(88.7)$ & $48(76.2)$ & $15(23.8)$ & \multirow[t]{2}{*}{0.79} \\
\hline Female & $8(11.3)$ & $7(87.5)$ & $1(12.5)$ & \\
\hline \multicolumn{5}{|l|}{ Smoking status } \\
\hline Non-smoker & $33(46.5)$ & $25(75.8)$ & $8(24.2)$ & \multirow[t]{2}{*}{0.75} \\
\hline Smoker & $38(53.5)$ & $30(78.9)$ & $8(21.1)$ & \\
\hline \multicolumn{5}{|c|}{ History of NMIBC } \\
\hline No & $39(54.9)$ & $31(79.5)$ & $8(20.5)$ & \multirow[t]{2}{*}{0.65} \\
\hline Yes & $32(45.1)$ & $24(75.0)$ & $8(25.0)$ & \\
\hline \multicolumn{5}{|l|}{ Associated pTis } \\
\hline No & $69(97.2)$ & $54(78.3)$ & $15(21.7)$ & \multirow[t]{2}{*}{0.35} \\
\hline Yes & $2(2.8)$ & $1(50.0)$ & $1(50.0)$ & \\
\hline \multicolumn{5}{|l|}{ Grade } \\
\hline Low & $25(35.2)$ & $21(84.0)$ & $4(16.0)$ & \multirow[t]{2}{*}{0.33} \\
\hline High & $46(64.8)$ & $34(73.9)$ & $12(26.1)$ & \\
\hline \multicolumn{5}{|l|}{ Tumor stage } \\
\hline $\mathrm{pTa}$ & $42(59.2)$ & $35(83.3)$ & $7(16.7)$ & \multirow[t]{2}{*}{0.15} \\
\hline pT1 & $29(40.8)$ & $20(69.0)$ & $9(31.0)$ & \\
\hline
\end{tabular}

${ }^{a} \chi^{2}$ test. PLEKHS1, pleckstrin homology domain-containing S1; NMIBC, non-muscle-invasive bladder cancer.

We investigated DNA mutations and mRNA expression in a large series of 154 bladder cancer cases. The results of DNA analysis were then validated in an independent second series $(n=181)$. In these two series, tumors were half non-muscle invasive and half muscle invasive. Characteristics of both populations are consistent with urothelial carcinoma presentation. Moreover, we observed the classical prognostic factors (TNM stage and grade).

We showed a high frequency of promoter DNA mutations for PLEKHS1, detected in about one-third of bladder tumors (NMIBC and MIBC). Our results are consistent with the princeps study of Weinhold et al describing PLEKHS1 DNA mutations in $8 / 20$ samples $(40 \%)$ of bladder cancer (8). This high rate of DNA mutations supports the concept of an essential involvement of this gene in bladder carcinogenesis, possibly similar to human TERT. It is also of interest as a biomarker to detect circulating tumor DNA that can be used for a variety of clinical and research purposes for bladder cancer.

In our study, PLEKHS1 mutations were particularly frequent with the basal MIBC phenotype, which is known to have poor prognosis but is associated with improved survival after neoadjuvant chemotherapy (14). Further research is needed to assess the role of PLEKHS1 in the chemosensitivity of MIBC.

PLEKHS1 mRNA was overexpressed in approximatively one-quarter of bladder tumors, regardless of stage and grade.
As well, the expression was particularly high in some tumor samples, but normal bladder tissue showed very low levels.

Although the rates of mutations appear to be almost the same as the proportion of mRNA overexpression, we did not find an association between DNA alterations and mRNA expression. This is an unexpected result suggesting that mutations in the PLEKHS1 promoter probably do not affect transcription and are not responsible for the increased mRNA expression in our bladder tumor series. Our results disagree with those of Weinhold et al., who showed PLEKHS1 mutations inversely correlated with mRNA expression level in a small series of 20 bladder tumors (8). In contrast, somatic mutations in the TERT promoter increased the expression of telomerase (13).

In NMIBC, PLEKHS1 overexpression was associated with poor prognosis and increased risk of progression to muscle-invasive disease. The overexpression remained an independent prognostic factor on multivariate analysis, which is quite remarkable. Indeed, except for TNM stage and pathological grade, we have no molecular markers to distinguish tumors that would be able to progress in muscle-invasive disease during follow-up. This is especially crucial for pT1 high-grade tumors, which have been shown to progress in 30 to $50 \%$ of cases during the first 5 years. Early identification of patients at risk of disease progression 
Table VIII. Association of clinicopathological variables and PLEKHS1 mRNA level with MIBC from the first series.

\begin{tabular}{|c|c|c|c|c|}
\hline Characteristic & $\begin{array}{c}\text { Total } \\
\text { population, } \mathrm{n}(\%)\end{array}$ & $\begin{array}{c}\text { PLEKHS1 mRNA } \\
\text { no overexpression, } \mathrm{n}(\%)\end{array}$ & $\begin{array}{c}\text { PLEKHS1 mRNA } \\
\text { overexpression, } \mathrm{n}(\%)\end{array}$ & $\mathrm{P}$-value $\mathrm{a}^{\mathrm{a}}$ \\
\hline Total & $83(100)$ & $60(72.3)$ & $23(27.7)$ & \\
\hline \multicolumn{5}{|l|}{ Age } \\
\hline$\geq 60$ & $61(73.5)$ & $44(72.1)$ & 17 (27.9) & \multirow[t]{2}{*}{0.96} \\
\hline$<60$ & $22(26.5)$ & $16(72.7)$ & $6(27.3)$ & \\
\hline \multicolumn{5}{|l|}{ Sex } \\
\hline Male & $66(79.5)$ & $45(68.2)$ & $21(31.8)$ & \multirow[t]{2}{*}{0.10} \\
\hline Female & $17(20.5)$ & $15(88.2)$ & $2(11.8)$ & \\
\hline \multicolumn{5}{|l|}{ Smoking status } \\
\hline Non-smoker & $34(41.0)$ & $23(67.6)$ & $11(32.4)$ & \multirow[t]{2}{*}{0.43} \\
\hline Smoker & $49(59.0)$ & $37(75.5)$ & $12(24.5)$ & \\
\hline \multicolumn{5}{|c|}{ History of NMIBC } \\
\hline No & $59(71.1)$ & $39(66.1)$ & $20(33.9)$ & \multirow[t]{2}{*}{0.05} \\
\hline Yes & $24(28.9)$ & $21(87.5)$ & $3(12.5)$ & \\
\hline \multicolumn{5}{|l|}{ Associated pTis } \\
\hline No & $73(88.0)$ & $52(71.2)$ & $21(28.7)$ & \multirow[t]{2}{*}{0.56} \\
\hline Yes & $10(12.0)$ & $8(80.0)$ & $2(20.0)$ & \\
\hline \multicolumn{5}{|l|}{ Grade } \\
\hline Low & $34(41.0)$ & $25(73.5)$ & $9(26.5)$ & \multirow[t]{2}{*}{0.83} \\
\hline High & $49(59.0)$ & $35(71.4)$ & $14(28.6)$ & \\
\hline \multicolumn{5}{|l|}{ Tumor stage } \\
\hline $\mathrm{pTa}$ & $58(69.9)$ & $39(68.4)$ & $19(32.8)$ & \multirow[t]{2}{*}{0.12} \\
\hline pT1 & $25(30.1)$ & $21(84.0)$ & $4(16.0)$ & \\
\hline
\end{tabular}

${ }^{a} \chi^{2}$ test. PLEKHS1, pleckstrin homology domain-containing S1; NMIBC, non-muscle-invasive bladder cancer.

Table IX.Cox proportional-hazards regression analysis of factors affecting progression-free survival with non-muscle-invasive bladder cancer.

\begin{tabular}{lccc}
\hline & \multicolumn{3}{c}{ Progression-free survival } \\
\cline { 2 - 4 } Prognostic factor & HR & $95 \%$ CI & P-value \\
\hline T stage & 3.92 & $(0.79-19.36)$ & 0.093 \\
Grade & 2.19 & $(0.20-24.58)$ & 0.52 \\
PLEKHS1 overexpression & 4.01 & $(1.11-14.50)$ & 0.034 \\
\hline
\end{tabular}

PLEKHS1, pleckstrin homology domain-containing S1; HR, hazard ratio.

may lead to more aggressive therapeutic strategies, such as early cystectomy. One of the main issues is the potential response of these tumors to BCG therapy. In our series, even though PLEKHS1 mRNA expression was three times higher with early recurrent or refractory tumor than other tumors, PLEKHS1 was not a significant predictive factor of response to BCG therapy. However, the small number of patients who received $B C G$ may explain the lack of statistical power in our study.
One limitation of our study is that a longer follow-up or a larger cohort of patients may be needed to show significance, especially for pT1 tumors and response to BCG. To confirm these data, prospective clinical studies associated with a molecular evaluation of tumors are needed. We tried to assess protein expression by western blot analysis and immunohistochemistry, but the two primary anti-PLEKHS1 antibodies used (i.e., HPA037583, Sigma and H00079949-T01, Abnova) showed no specific protein bands on western blot analysis or on immunostaining (data not shown), which suggests no qualitative antibody available for PLEKHS1. Functional analyses should probably be done in parallel to investigate the role of PLEKHS1 in carcinogenesis. Recently, Grossmann et al. identified an interaction between PIK3R3 (p55c regulatory subunit of PI3 kinase) and PLEKHS1 (15), but the significance of this protein interaction remains uncertain. In our series, even if PLEKHS1 mutations were significantly more frequent with the basal than non-basal MIBC phenotype, we did not identify any other associated gene or pathway alterations. Therefore, despite its prognostic value, PLEKHS1 cannot be considered a therapeutic target at this time.

Our results support the involvement of PLEKHS1 in bladder carcinogenesis. DNA mutations were observed in almost one-third of bladder cancers and approximately one quarter of NMIBC and MIBC tumors showed mRNA 
overexpression. In MIBC, PLEKHS1 mutations seem frequent with the basal phenotype. In NMIBC, PLEKHSI overexpression may be an independent prognostic factor of progression to muscle-invasive disease. Our study has many biases since it is a retrospective clinical study, small cohort and can only be considered as a preliminary study. The clinical interest remains to be demonstrated by a prospective study centered on high grade NMIBC. Further studies are needed to dissect the mechanisms of action and the specific role of PLEKHSI in bladder carcinogenesis and to develop therapeutic inhibitors.

\section{Acknowledgements}

Not applicable.

\section{Funding}

No funding was received.

\section{Availability of data and materials}

The datasets used and/or analyzed during the current study are available from the corresponding author on reasonable request.

\section{Authors' contributions}

GP and CLG contributed to the acquisition and interpretation of data, and manuscript writing. SV, AS and FL contributed to the acquisition of data. FR, YA, NBD, MZ and BT aquired the data. DD contributed to acquisition and interpretation of data. IB contributed to the conception and design of the study, and interpretation of data. All authors read and approved the final manuscript.

\section{Ethics approval and consent to participate}

The present study was approved by the local ethics and research committee of Mondor and Foch Hospitals, Centre d'Éthique Clinique de l'Hôpital Cochin (descriptive retrospective study). All patients provided written informed consent.

\section{Patient consent for publication}

All patients provided informed consent.

\section{Competing interests}

The authors declare that they have no competing interests.

\section{References}

1. Torre LA, Bray F, Siegel RL, Ferlay J, Lortet-Tieulent J and Jemal A: Global cancer statistics, 2012. CA Cancer J Clin 65 87-108, 2015
2. Lebret T,Hervé JM, Yonneau L,Barré P, Lugagne PM,Butreau M, Molinié V and Botto H: Study of survival after cystectomy for bladder cancer. Report of 504 cases. Prog Urol 10: 553-560, 2000 (In French).

3. Salvi S, Calistri D, Gurioli G, Carretta E, Serra L, Gunelli R, Zoli W and Casadio V: Copy number analysis of 24 oncogenes: MDM4 identified as a putative marker for low recurrence risk in non muscle invasive bladder cancer. Int J Mol Sci 15: 12458-12468, 2014.

4. Cancer Genome Atlas Research Network: Comprehensive molecular characterization of urothelial bladder carcinoma. Nature 507: 315-322, 2014.

5. Williams SV, Hurst CD and Knowles MA: Oncogenic FGFR3 gene fusions in bladder cancer. Hum Mol Genet 22: 795-803, 2013.

6. Massari F, Bria E, Ciccarese C, Munari E, Modena A,Zambonin V, Sperduti I, Artibani W, Cheng L, Martignoni G, et al: Prognostic value of beta-tubulin-3 and c-Myc in muscle invasive urothelial carcinoma of the bladder. PLoS One 10: e0127908, 2015.

7. Pignot $\mathrm{G}$, le Goux $\mathrm{C}$ and Bieche I: Recent advances in bladder urothelial carcinogenesis. Bull Cancer 102: 1020-1035, 2015 (In French).

8. Weinhold N, Jacobsen A, Schultz N, Sander C and Lee W: Genome-wide analysis of noncoding regulatory mutations in cancer. Nat Genet 46: 1160-1165, 2014.

9. Sobin L, Gospodarowicz M and Wittekind C (eds.): TNM Classification of Malignant Tumors. John Wiley and Sons, Hoboken, NJ, USA, pp 262-265, 2009.

10. Molinié V: Classification of bladder tumors in 2006. In: Prog Urol FMC, pp16: 7-10, 2006.

11. Rebouissou S, Bernard-Pierrot I, de Reyniès A, Lepage ML, Krucker C, Chapeaublanc E, Hérault A, Kamoun A, Caillault A, Letouzé E, et al: EGFR as a potential therapeutic target for a subset of muscle-invasive bladder cancers presenting a basal-like phenotype. Sci Transl Med 6: 244ra91, 2014.

12. Pignot G, Bieche I, Vacher S, Güet C, Vieillefond A, Debré B, Lidereau R and Amsellem-Ouazana D: Large-scale real-time reverse transcription-PCR approach of angiogenic pathways in human transitional cell carcinoma of the bladder: Identification of VEGFA as a major independent prognostic marker. Eur Urol 56: 678-688, 2009.

13. Killela PJ,Reitman ZJ, Jiao Y, Bettegowda C, Agrawal N, Diaz LA Jr, Friedman AH, Friedman H, Gallia GL, Giovanella BC, et al: TERT promoter mutations occur frequently in gliomas and a subset of tumors derived from cells with low rates of self-renewal. Proc Natl Acad Sci USA 110: 6021-6026, 2013.

14. McConkey DJ, Choi W, Shen Y, Lee IL, Porten S, Matin SF, Kamat AM, Corn P, Millikan RE, Dinney C, et al: A prognostic gene expression signature in the molecular classification of chemotherapy-naïve urothelial cancer is predictive of clinical outcomes from neoadjuvant chemotherapy: A phase 2 trial of dose-dense methotrexate, vinblastine, doxorubicin, and cisplatin with bevacizumab in urothelial cancer. Eur Urol 69: 855-862, 2016.

15. Grossman HB, Natale RB, Tangen CM, Speights VO, Vogelzang NJ, Trump DL, deVere White RW, Sarosdy MF, Wood DP Jr, Raghavan D and Crawford ED: Neoadjuvant chemotherapy plus cystectomy compared with cystectomy alone for locally advanced bladder cancer. N Engl J Med 349: 859-866, 2003.

This work is licensed under a Creative Commons Attribution-NonCommercial-NoDerivatives 4.0 International (CC BY-NC-ND 4.0) License. 